\title{
Liver metastases of neuroendocrine tumours; early reduction of tumour load to improve life expectancy Liesbeth M Veenendaal ${ }^{1}$, Inne HM Borel Rinkes ${ }^{1}$, Cornelis JM Lips ${ }^{2}$ and Richard van Hillegersberg*1
}

\author{
Address: ${ }^{1}$ Department of Surgery, University Medical Center Utrecht, The Netherlands and ${ }^{2}$ Department of Clinical Endocrinology, University \\ Medical Center Utrecht, The Netherlands \\ Email: Liesbeth M Veenendaal - l.m.veenendaal@umcutrecht.nl; Inne HM Borel Rinkes - i.h.m.borelrinkes@umcutrecht.nl; \\ Cornelis JM Lips - lips05@zonnet.nl; Richard van Hillegersberg* - r.vanhillegersberg@umcutrecht.nl \\ * Corresponding author
}

Published: 26 June 2006

World Journal of Surgical Oncology 2006, 4:35 doi:10.1 186/1477-7819-4-35

This article is available from: http://www.wjso.com/content/4/I/35

(C) 2006 Veenendaal et al; licensee BioMed Central Ltd.

This is an Open Access article distributed under the terms of the Creative Commons Attribution License (http://creativecommons.org/licenses/by/2.0), which permits unrestricted use, distribution, and reproduction in any medium, provided the original work is properly cited.
Received: 07 April 2006

Accepted: 26 June 2006

\begin{abstract}
Background: Neuroendocrine tumours frequently metastasize to the liver. Although generally slowly progressing, hepatic metastases are the major cause of carcinoid syndrome and ultimately lead to liver dysfunction, cardiac insufficiency and finally death.

Methods: A literature review was performed to define the optimal treatment strategy and workup in patients with neuroendocrine hepatic metastases. Based on this, an algorithm for the management of these patients was established.

Results: Platelet serotonin and chromogranin $\mathrm{A}$ are useful biomarkers for detection and followup of neuroendocrine tumour. Helical computed tomography and somatostatin receptor scintigraphy are the most sensitive diagnostic modalities. Surgical debulking is an accepted approach for reducing hormonal symptoms and to establish better conditions for medical treatment, but is frequently impossible due to the extent of disease. A novel approach is the local ablation of tumour by thermal coagulation using therapies such as radiofrequency ablation (RFA) or laser induced thermotherapy (LITT). These techniques preserve normal liver tissue. There is a tendency to destroy metastases early in the course of disease, thereby postponing or eliminating the surgically untreatable stage. This can be combined with postoperative radioactive octreotide to eliminate small multiple metastases. In patients with extensive metastases who are not suitable for local destruction, systemic therapy by octreotide, I3| I-MIBG treatment or targeted chemo- and radiotherapy should be attempted. A final option for selective patients is orthotopic liver transplantation.
\end{abstract}

Conclusion: Treatment for patients with neuroendocrine hepatic metastases must be tailored for each individual patient. When local ablative therapies are used early in the course of the disease, the occurrence of carcinoid syndrome with end stage hepatic disease can be postponed or prevented. 


\section{Background}

Carcinoids are neuroendocrine tumours that arise from neoplastic proliferation of enterochromaffin or Kulchitsky cells [1]. In 1963, carcinoids were classified according to their embryologic site of origin as foregut carcinoids (respiratory tract, stomach, duodenum, biliary system and pancreas), midgut carcinoids (small intestine, appendix, cecum, and proximal colon), and hindgut carcinoids (distal colon and rectum) [2]. According to the WHO classification in 2000, distinction was made between welldifferentiated neuroendocrine tumours (benign behaviour or uncertain malignant potential, <2\% Ki67 positive cells), well-differentiated neuroendocrine carcinomas (low grade malignancy, presence of metastasis and/or invasiveness), and poorly differentiated neuroendocrine carcinomas of high-grade malignancy (usually small cell, $>15 \%$ Ki67 positive cells) [3]. Ki67 is an immunohistochemical biomarker for cell proliferation.

Neuroendocrine hepatic metastases represent about 10\% of all hepatic metastatic neoplasm's [4]. These metastases occur in about 25-90\% of patients with neuroendocrine tumours. Although these tumours run a rather indolent course, the 5-year survival of patients with neuroendocrine tumours and liver metastases is $40 \%$ compared with 75-99\% in those free of liver metastases [5-7]. Neuroendocrine liver metastases often progress slowly but may cause significant symptoms due to their size and/or hormone production. Ultimately the hepatic tissue is replaced by tumour, causing mechanical pressure to surrounding tissues, liver dysfunction, cardiac failure and finally death. Manifestations of the carcinoid syndrome usually occur in patients with liver metastases due to production and release of serotonin directly in the blood stream. Classically, the carcinoid syndrome is characterised by episodic flushing, tachycardia, diarrhoea and bronchospasm [8]. Treatment of neuroendocrine hepatic metastases is aiming at symptomatic improvement and reduction of hormonal hypersecretion by elimination of the tumour. However, the most effective management and timing of treatment remains unclear $[9,10]$. Here, we have reviewed the literature and used our own experience to provide a balanced guideline for imaging and management of patients with neuroendocrine hepatic metastases.

\section{Biochemical diagnosis}

Neuroendocrine tumours of the small intestine produce large quantities of serotonin (5-hydroxytryptamine), reflected in raised levels of platelet serotonin and a high urinary excretion of 5-hydroxyindoleacetic acid (5-HIAA) $[11,12]$. The platelet serotonin concentration is more sensitive in the detection of carcinoid tumours than urinary 5-HIAA, particularly in tumours with relatively low serotonin production $[13,14]$. Circulating free serotonin is removed very rapidly and effectively by the liver. In con- trast to urinary 5-HIAA, platelet serotonin is not effected by serotonin-containing diet [15]. Hence platelet serotonin is the most discriminating marker for detection of most neuroendocrine tumours. However, in hindgut carcinoids, hydroxylase and decarboxylase are absent and no serotonin is produced.

Plasma chromogranin A ( $\mathrm{CgA})$ has been claimed the most sensitive and specific marker of tumour volume [16]. CgA is a precursor for several peptides and is stored in secretory granules of neuroendocrine tissue [17]. Circulating CgA allows early detection of persistent or recurrent neuroendocrine tumours [18]. The highest CgA levels were noted in metastatic midgut lesions [19].

Both tumour markers, platelet serotonin and CgA, can be reliably used for diagnosis of neuroendocrine tumour and for monitoring the outcome of treatment in individual patients.

\section{Work-up of patients with neuroendocrine hepatic metastases}

Several imaging modalities are available to detect hepatic metastases and their primary neuroendocrine tumours. Conventional ultrasonography (US), computed tomography (CT), magnetic resonance imaging (MRI) and somatostatin receptor scintigraphy (SRS) are the cornerstones for the localisation of neuroendocrine tumours with sensitivities of respectively 46\%, 42\%, 43\% and 90\% [20-23]. The use of helical computed tomography (hCT) has increased the diagnostic sensitivity in the localisation of both primary (94\%) and metastatic tumour (lymph node $69 \%$, liver 94\%) [24]. As somatostatin receptor subtype 2 is present in almost $80 \%$ of neuroendocrine tumours, binding 111Indium-labelled octreotide can be used for both disease staging and to indicate whether or not somatostatin analogues can be used in the treatment of these tumours [25]. SRS is very helpful in detecting bone and lung metastases and thereby aids in confirming or refuting the presence of extrahepatic disease. Based on these considerations, both hCT and SRS should be performed in all patients prior to treatment.

\section{Treatment modalities Surgical resection}

Surgical resection is to be considered when no extrahepatic disease is present. Hemihepatectomy or segmental resection is feasible when metastases are solitary and resection can be radical with enough functional liver tissue remaining. Symptomatic response rates have been reported to be $90 \%$ for a mean duration of 19.3 months after surgical resection [26]. Unfortunately, neuroendocrine metastases are usually multiple and diffuse and therefore resection is often impossible. Furthermore, in most patients treated by surgical resection with curative 

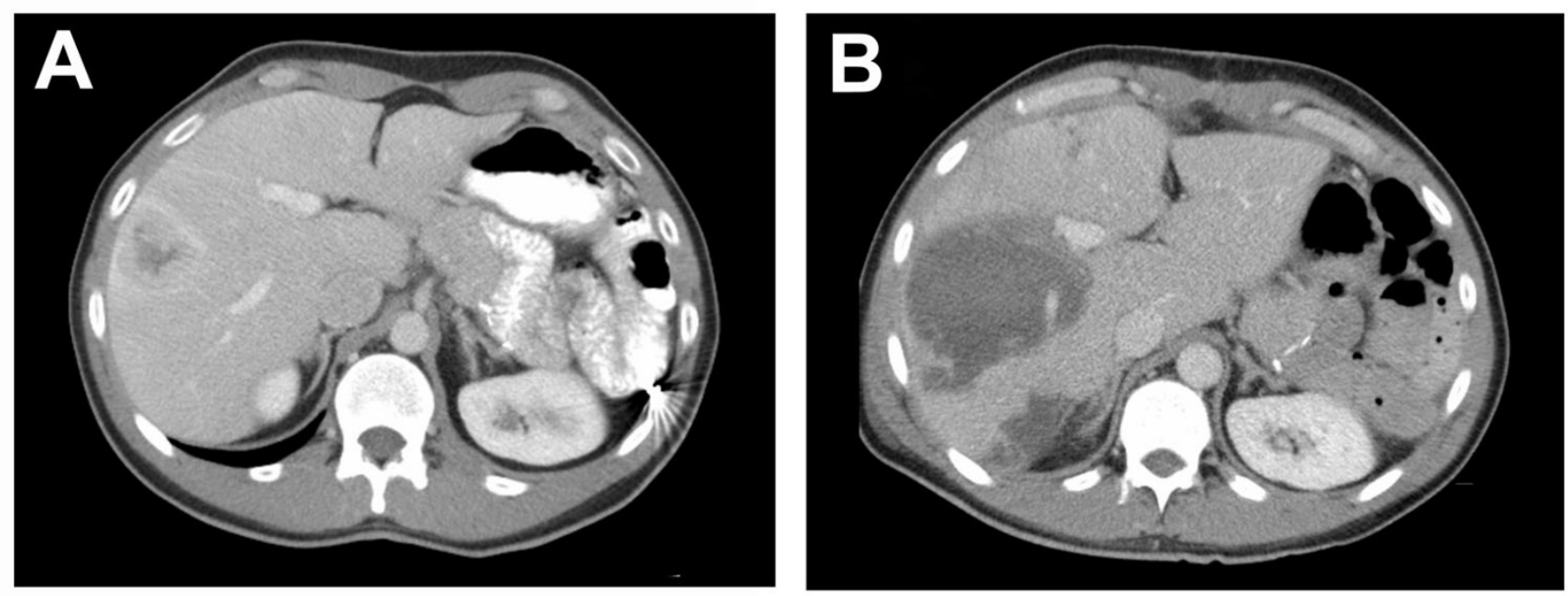

\section{Figure I}

CT scan of the liver of a 34-year old man with metastases of a neuroendocrine tumour of the pancreas. Before LITT the CT scan shows a metastases of $4.7 \mathrm{~cm}$ in diameter in segment VII and a second metastases of $2.0 \mathrm{~cm}$ in diameter in segment VII subcapsular (not visible) of the liver (figure 2A). Control CT scan one week after LITT showing a coagulation lesion in segment VII of $9.0 \mathrm{~cm}$ in diameter and subcapsular in segment VII of $4.8 \mathrm{~cm}$ in diameter (figure 2B).

intent, additional metastases develop that presumably were occult at the time of surgery [26]. Therefore even in resectable cases, liver tissue sparing therapies should be considered, allowing future repeated treatment.

\section{Local ablative therapy}

Local therapy using radiofrequency ablation (RFA) or laser induced thermotherapy (LITT) is a well-established treatment for unresectable hepatocellular carcinomas and liver metastases from colorectal carcinomas [27,28]. A few small series and case reports have also shown good response in neuroendocrine hepatic metastases [29-33]. Up until now, a disadvantage of these therapies has been the relatively small volume of tissue that can be coagulated. Clinical trials with RFA have shown that complete tumour eradication is more likely to occur with small tumours, i.e. diameter $\leq 4 \mathrm{~cm}$, than with large tumours [34]. With the use of simultaneous multiple fiber LITT or next generation bipolar RFA, we have been able to ablate tumours as large as $7 \mathrm{~cm}$ in diameter [35] (Figure 1). Furthermore, up to 7 lesions at one time may be ablated using specialized techniques to increase lesion size [36]. It has been reported that cytoreduction of $\geq 90 \%$ is adequate for durable symptomatic relief [9]. In our most recent strategy, we aim at complete destruction of the intrahepatic tumour to prevent the occurrence of surgically untreatable disease. The largest reported study of 34 patients with neuroendocrine hepatic metastases treated with RFA showed symptom relief in $95 \%$ of these patients with significant or complete symptom control in $80 \%$, for a mean of 10 months [29]. Even in patients with extrahe- patic disease and liver metastases ablation may also provide symptom relief [29]. The complication rate is $5-10 \%$ and the mortality rate is about $0.5 \%$ [37-39]. Therefore these techniques are especially suitable for repeated treatment in patients in which local recurrence or new metastases developing during follow up.

All invasive procedures during surgery such as liver resection and ablation and even anaesthesia can induce hormone release and even provoke a life-threatening carcinoid crisis [40]. In the severe crisis of carcinoid syndrome the flush is usually accompanied by hypotension and occasionally shock. Injection of octreotide, the longacting analog of somatostatin, usually prevents or aborts this vasomotor reaction [41]. Studies have shown that the use of octreotide intraoperatively for patients with metastatic carcinoid tumours undergoing surgery with manipulation of tumour is associated with a decreased frequency of intraoperative complications $[42,43]$.

\section{Arterial embolisation}

Hepatic arterial embolisation with or without chemotherapy is a palliative option for those unresectable lesions in which the predominant mass of tumour is localised in one of the liver lobes. In the past, more radical blunt techniques to occlude the main hepatic artery were used. However, recently, superselective techniques have become available with the advantage of leaving the main segmental arteries open. Contraindications of hepatic arterial embolisation include complete portal vein occlusion, hepatic failure and previous biliary anastomoses 


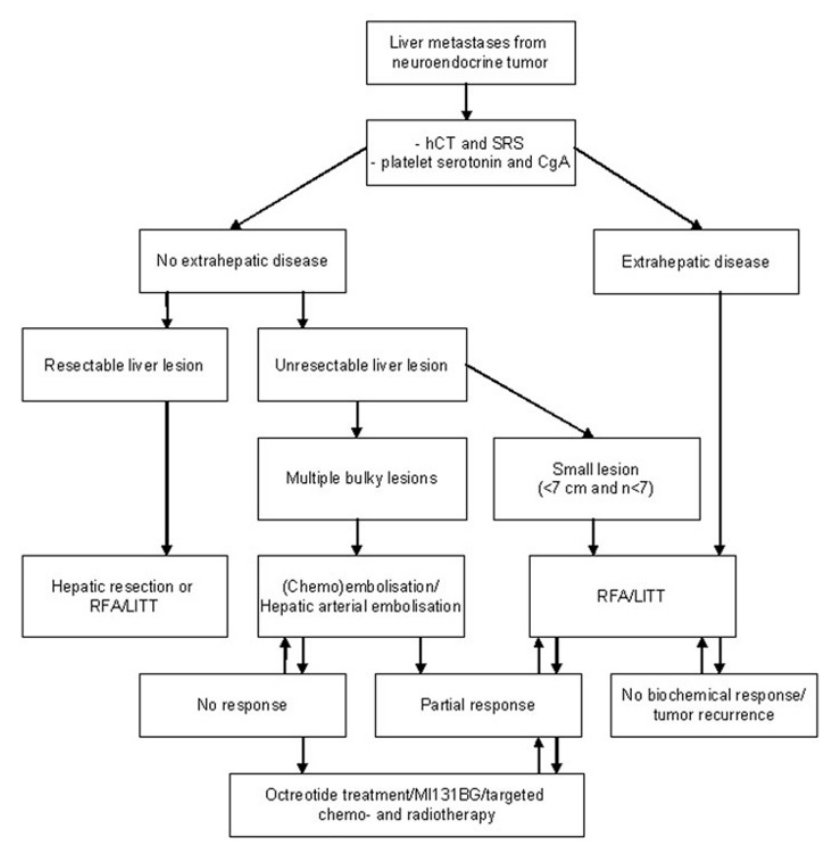

Figure 2

Protocol for management of patients with neuroendocrine hepatic metastases. CT, computed tomography; MRI, magnetic resonance imaging; SRS, somatostatin receptor scintigraphy; RFA, radiofrequency ablation; LITT, laser induced thermotherapy; ${ }^{3}$ II-MIBG, lodine-|3| metaiodobenzylguanidine.

[44]. Symptomatic improvement after hepatic arterial embolisation is reported to occur in $64-90 \%[45,46]$. Reports on chemoembolisation show a slight better biochemical response and tumour response than hepatic artery embolisation [47]. Embolisation techniques are associated with mortality rates of about $5 \%$ and almost all patients develop the 'postembolic syndrome' (elevated liver function tests and fever) although mostly transient and in different grades of severity [48-50]. In addition, serious complications have occurred in about $10 \%$ of patients treated with hepatic embolisation for neuroendocrine tumours [51]. Complications can be reduced by prophylactic octreotide infusion during the procedure and the use of forced diuresis during and after the embolisation. In case of partial or no response, supplementary embolisation or additional RFA or LITT could be an option. In selected cases with good response to embolisation a partial hepatic resection may be considered.

\section{Pharmacological therapy}

Pharmacological therapy consists of long-lasting octreotide injections, Iodine-131 metaiodobenzylguanidine (131 I-MIBG), interferon- $\alpha$ (IFN- $\alpha$ ) or targeted chemo- and radiotherapy. Octreotide is a somatostatin analogue and appears to be an efficacious treatment for carcinoid syndrome, reducing symptoms in more than $70 \%$ of patients $[52,53]$. Some patients with partial response after local ablation have relief of symptoms by additional treatment with octreotide [37]. Prolonged symptomatic relief can be provided by ${ }^{131}$ I-MIBG therapy. In individual cases, improved quality of life may be obtained [54]. Even improved survival was seen by symptomatic response to ${ }^{131}$ I-MIBG treatment [55]. The clinical benefit of IFN- $\alpha$ treatment has been limited by their modest anti-tumour effect as well as serious side-effects [56,57]. In addition, combination treatment with octreotide and IFN- $\alpha$ showed little advantage. Biochemical responses were observed in $72-77 \%$, however no objective tumour regression was observed $[57,58]$. A promising approach is the concept of somatostatin receptor (SSTR)-mediated chemo-or radiotherapy of SSTR-expressing metastatic carcinoid. Currently, clinical trials with cytotoxic compounds, such as methotrexate and doxorubicin, linked to an analog of somotostatin are under way $[59,60]$. Also promising is targeted SSRT-mediated radiotherapy using radionuclides such as ${ }^{90} \mathrm{Y}$ and ${ }^{177} \mathrm{Lu}$. Experimental studies in patients who have somatostatin-positive tumours show complete remission by the use of tetra-azacyclododecane tetra-acetic acid $\mathrm{Tyr}^{3}$-octreotide [61]. After surgical reduction of tumour load, repeated intermediate-dosage ${ }^{90} \mathrm{Y}$, Tyr-octreotide, ${ }^{177} \mathrm{Lu}$ or ${ }^{131}$ I-MIBG treatment appears to be a reliable and well-tolerated radionuclide therapy and might be a useful adjunct in patients with malignant neuroendocrine carcinoma, providing long-lasting palliation and prolonged survival [62].

\section{Liver transplantation}

Young patients with surgically unresectable tumours, hepatomegaly and uncontrollable symptoms, in whom all other therapies have been unsuccessful, may benefit from liver transplantation [63]. However, liver transplantation for metastatic disease is controversial and in most cases even contraindicated, as the results have been poor due to complex operative procedures [64-66]. Well differentiated tumours and a low proliferation rate (Ki67<10\%) are important selection criteria [67]. Overall, post-operative mortality of $19 \%$ is reported in a group of 31 patients undergoing orthotopic liver transplantation for metastatic neuroendocrine tumours [65]. In the same study, $50 \%$ of the carcinoid patients suffered from one or more major complications i.e. peritoneal bleeding, acute/ chronic rejection and acute pancreatitis [65].

\section{Conclusion}

Hepatic metastases are frequently encountered in patients with digestive endocrine tumours and their presence plays an important role in quality of life and overall prognosis. Tailored multimodality treatment is the key to increase survival and achieve good palliation in patients with 
hepatic metastases from neuroendocrine tumours. A flow sheet such as presented in figure 2 can be helpful in the decision of choice of treatment. Determination of platelet serotonin and plasma CgA is useful for detection of neuroendocrine tumour and to evaluate therapy efficiency. Visualisation of neuroendocrine hepatic metastases should be performed by hCT/MRI and SRS. Determination of platelet serotonin and plasma $\mathrm{CgA}$ is useful for detection of neuroendocrine tumour and to evaluate therapy efficiency. The proliferation marker Ki67 is a very important tool in guiding the type of treatment. Surgery is the treatment of choice for hepatic metastases however cure is frequently impossible due to the extent of disease. Treatment aimed at cytoreduction of hepatic metastasis and diminished secretion of bioactive amines may achieve good palliation. Tumour destruction by RFA or LITT provides a novel liver preserving option. These techniques will now be used more often as liver preserving option to treat patients early in the course of their disease postponing drug intervention and preventing the end stage carcinoid syndrome and thereby improving life expectancy.

\section{Competing interests}

The author(s) declare that they have no competing interests.

\section{Authors' contributions}

$\mathbf{L V}$ reviewed the literature and drafted the manuscript. IBR and CL critically reviewed the paper and were involved in the preparation of the final manuscript. RH was involved in the conception of the work and manuscript preparation. All authors read and approved final version for publication.

\section{References}

I. Rindi G, Bordi C: Highlights of the biology of endocrine tumours of the gut and pancreas. Endocr Relat Cancer 2003, 10:427-436.

2. Williams ED, Sandler M: The classification of carcinoid tum ours. Lancet 1963, I:238-239.

3. Solcia E, Kloppel G, Sobhin LH: Histological typing of endocrine tumours. In International histological classification of endocrine tumours Springer-Verlag: New York; 2000.

4. Benevento A, Boni L, Frediani L, Ferrari A, Dionigi R: Result of liver resection as treatment for metastases from noncolorectal cancer. J Surg Oncol 2000, 74:24-29.

5. Godwin JD: Carcinoid tumors. An analysis of 2,837 cases. Cancer 1975, 36:560-569.

6. McDermott EW, Guduric B, Brennan MF: Prognostic variables in patients with gastrointestinal carcinoid tumours. $\mathrm{Br}$ J Surg 1994, 8 I: 1007-1009.

7. Zeitels J, Naunheim K, Kaplan EL, Straus F: Carcinoid tumors: a 37-year experience. Arch Surg 1982, I I 7:732-737.

8. Oates JA: The carcinoid syndrome. N Engl J Med 3 15:702-704. II-9-1986

9. Chamberlain RS, Canes D, Brown KT, Saltz L, Jarnagin W, Fong Y, Blumgart LH: Hepatic neuroendocrine metastases: does intervention alter outcomes? J Am Coll Surg 2000, 190:432-445.

10. Chen H, Hardacre JM, Uzar A, Cameron JL, Choti MA: Isolated liver metastases from neuroendocrine tumors: does resection prolong survival? J Am Coll Surg 1998, 187:88-92.
II. Farthing MJ: 5-Hydroxytryptamine and 5-hydroxytryptamine3 receptor antagonists. Scand J Gastroenterol Suppl 1991, 188:92-100.

12. Kema IP, de Vries EG, Slooff MJ, Biesma B, Muskiet FA: Serotonin, catecholamines, histamine, and their metabolites in urine, platelets, and tumor tissue of patients with carcinoid tumors. Clin Chem 1994, 40:86-95.

13. Meijer WG, Kema IP, Volmer M, Willemse PH, de Vries EG: Discriminating capacity of indole markers in the diagnosis of carcinoid tumors. Clin Chem 2000, 46:1588-1596.

14. Carling RS, Degg TJ, Allen KR, Bax ND, Barth JH: Evaluation of whole blood serotonin and plasma and urine 5-hydroxyindole acetic acid in diagnosis of carcinoid disease. Ann Clin Biochem 2002, 39:577-582.

15. Kema IP, Schellings AM, Meiborg G, Hoppenbrouwers CJ, Muskiet FA: Influence of a serotonin- and dopamine-rich diet on platelet serotonin content and urinary excretion of biogenic amines and their metabolites. Clin Chem 1992, 38:1730-I 736.

16. Bajetta E, Ferrari L, Martinetti A, Celio L, Procopio G, Artale S, Zilembo N, Di Bartolomeo M, Seregni E, Bombardieri E: Chromogranin $A$, neuron specific enolase, carcinoembryonic antigen, and hydroxyindole acetic acid evaluation in patients with neuroendocrine tumors. Cancer 86:858-865. 1-9-1999

17. Hutton JC, Davidson HW, Peshavaria M: Proteolytic processing of chromogranin $A$ in purified insulin granules. Formation of a $20 \mathrm{kDa} \mathrm{N}$-terminal fragment (betagranin) by the concerted action of a Ca2+-dependent endopeptidase and carboxypeptidase H (EC 3.4.17. I0). Biochem J 244:457-464. I-6-1987

18. Pirker RA, Pont J, Pohnl R, Schutz W, Griesmacher A, Muller MM: Usefulness of chromogranin $A$ as a marker for detection of relapses of carcinoid tumours. Clin Chem Lab Med 1998, 36:837-840.

19. Nobels FR, Kwekkeboom DJ, Coopmans W, Schoenmakers CH, Lindemans J, De Herder WW, Krenning EP, Bouillon R, Lamberts SW: Chromogranin $A$ as serum marker for neuroendocrine neoplasia: comparison with neuron-specific enolase and the alpha-subunit of glycoprotein hormones. J Clin Endocrinol Metab 1997, 82:2622-2628.

20. Gibril F, Reynolds JC, Doppman JL, Chen CC, Venzon DJ, Termanini B, Weber HC, Stewart CA, Jensen RT: Somatostatin receptor scintigraphy: its sensitivity compared with that of other imaging methods in detecting primary and metastatic gastrinomas. A prospective study. Ann Intern Med 125:26-34. I-71996

21. Chiti A, Fanti S, Savelli G, Romeo A, Bellanova B, Rodari M, van Graafeiland BJ, Monetti N, Bombardieri E: Comparison of somatostatin receptor imaging, computed tomography and ultrasound in the clinical management of neuroendocrine gastroentero-pancreatic tumours. Eur J Nucl Med 1998, 25: I 396-I 403.

22. Frucht H, Doppman JL, Norton JA, Miller DL, Dwyer AJ, Frank JA, Vinayek R, Maton PN, Jensen RT: Gastrinomas: comparison of MR imaging with CT, angiography, and US. Radiology 1989, 171:713-717.

23. Termanini B, Gibril F, Reynolds JC, Doppman JL, Chen CC, Stewart $C A$, Sutliff VE, Jensen RT: Value of somatostatin receptor scintigraphy: a prospective study in gastrinoma of its effect on clinical management. Gastroenterology 1997, I | 2:335-347.

24. Panzuto F, Falconi M, Nasoni S, Angeletti S, Moretti A, Bezzi M, Gualdi G, Polettini E, Sciuto R, Festa A, Scopinaro F, Corleto VD, Bordi C, Pederzoli P, Delle FG: Staging of digestive endocrine tumours using helical computed tomography and somatostatin receptor scintigraphy. Ann Oncol 2003, | 4:586-59|.

25. Kwekkeboom DJ, Krenning EP, Bakker WH, Oei HY, Kooij PP, Lamberts SW: Somatostatin analogue scintigraphy in carcinoid tumours. Eur J Nucl Med 1993, 20:283-292.

26. Que FG, Sarmiento JM, Nagorney DM: Hepatic surgery for metastatic gastrointestinal neuroendocrine tumors. Cancer Control 2002, 9:67-79.

27. Liu LX, Zhang WH, Jiang HC: Current treatment for liver metastases from colorectal cancer. World J Gastroenterol 2003, 9:193-200.

28. Wong SL, Edwards MJ, Chao C, Simpson D, McMasters KM: Radiofrequency ablation for unresectable hepatic tumors. Am J Surg 200I, 182:552-557. 
29. Berber E, Flesher N, Siperstein AE: Laparoscopic radiofrequency ablation of neuroendocrine liver metastases. World J Surg 2002, 26:985-990.

30. Hellman P, Ladjevardi S, Skogseid B, Akerstrom G, Elvin A: Radiofrequency tissue ablation using cooled tip for liver metastases of endocrine tumors. World J Surg 2002, 26:1052-1056.

31. Wessels FJ, Schell SR: Radiofrequency ablation treatment of refractory carcinoid hepatic metastases. J Surg Res 200I, 95:8-12.

32. Siperstein AE, Rogers SJ, Hansen PD, Gitomirsky A: Laparoscopic thermal ablation of hepatic neuroendocrine tumor metastases. Surgery 1997, I 22: I |47-I I54.

33. Meij V, Zuetenhorst JM, van Hillegersberg R, Kroger R, Prevoo W, van Coevorden F, Taal BG: Local treatment in unresectable hepatic metastases of carcinoid tumors: Experiences with hepatic artery embolization and radiofrequency ablation. World ] Surg Oncol 2005, 3:75.

34. de Baere T, Elias D, Dromain C, Din MG, Kuoch V, Ducreux M, Boige V, Lassau N, Marteau V, Lasser P, Roche A: Radiofrequency ablation of 100 hepatic metastases with a mean follow-up of more than I year. AJR Am J Roentgenol 2000, I75:1619-1625.

35. Veenendaal LM, de Jager A, Stapper G, Borel Rinkes IHM, van Hillegersberg R: Multiple fiber laser-induced thermotherapy for ablation of large intrahepatic tumors. Photomed Laser Surg 2006, 24:3-9.

36. Veenendaal LM, Borel Rinkes IHM, van Hillegersberg R: Multipolar radiofrequency ablation of large hepatic metastases of endocrine tumours. Eur / Gastroenterol Hepatol 2006, 18:89-92.

37. Henn AR, Levine EA, McNulty W, Zagoria RJ: Percutaneous radiofrequency ablation of hepatic metastases for symptomatic relief of neuroendocrine syndromes. AJR Am J Roentgenol 2003, 181:1005-1010.

38. Curley SA, Marra P, Beaty K, Ellis LM, Vauthey JN, Abdalla EK, Scaife C, Raut C, Wolff R, Choi H, Loyer E, Vallone P, Fiore F, Scordino F, De RV, Orlando R, Pignata S, Daniele B, Izzo F: Early and late complications after radiofrequency ablation of malignant liver tumors in 608 patients. Ann Surg 2004, 239:450-458.

39. Poon RT, Ng KK, Lam CM, Ai V, Yuen J, Fan ST, Wong J: Learning curve for radiofrequency ablation of liver tumors: prospective analysis of initial 100 patients in a tertiary institution. Ann Surg 2004, 239:44I-449.

40. Wettstein M, Vogt C, Cohnen M, Brill N, Kurz AK, Modder U, Haussinger D: Serotonin release during percutaneous radiofrequency ablation in a patient with symptomatic liver metastases of a neuroendocrine tumor. Hepatogastroenterology 2004, 5 I:830-832

4I. Warner RR, Mani S, Profeta J, Grunstein E: Octreotide treatment of carcinoid hypertensive crisis. Mt Sinai I Med I994, 6 I:349-355.

42. Veall GR, Peacock JE, Bax ND, Reilly CS: Review of the anaesthetic management of 21 patients undergoing laparotomy for carcinoid syndrome. Br J Anaesth 1994, 72:335-34I.

43. Kinney MA, Warner ME, Nagorney DM, Rubin J, Schroeder DR, Maxson PM, Warner MA: Perianaesthetic risks and outcomes of abdominal surgery for metastatic carcinoid tumours. $\mathrm{Br}$ Anaesth 200I, 87:447-452.

44. Roche A: [Hepatic chemo-embolization]. Bull Cancer 1989, 76: $1029-1037$

45. Schell SR, Camp ER, Caridi JG, Hawkins IF Jr: Hepatic artery embolization for control of symptoms, octreotide requirements, and tumor progression in metastatic carcinoid tumors. J Gastrointest Surg 2002, 6:664-670.

46. Carrasco CH, Charnsangavej C, Ajani J, Samaan NA, Richli W, Wallace $S$ : The carcinoid syndrome: palliation by hepatic artery embolization. AJR Am J Roentgenol 1986, I47: I49-154.

47. Diamandidou E, Ajani JA, Yang DJ, Chuang VP, Brown CA, Carrasco HC, Lawrence DD, Wallace S: Two-phase study of hepatic artery vascular occlusion with microencapsulated cisplatin in patients with liver metastases from neuroendocrine tumors. AJR Am J Roentgenol 1998, 170:339-344.

48. O'Toole D, Maire F, Ruszniewski P: Ablative therapies for liver metastases of digestive endocrine tumours. Endocr Relat Cancer 2003, 10:463-468.

49. Kress O, Wagner HJ, Wied M, Klose KJ, Arnold R, Alfke H: Transarterial chemoembolization of advanced liver metastases of neuroendocrine tumors - a retrospective single-center analysis. Digestion 2003, 68:94-10।.
50. Kolmannskog F, Kolbenstvedt AN, Schrumpf E, Hanssen LE: Side effects and complications after hepatic artery embolization in the carcinoid syndrome. Scand J Gastroenterol |99|, 26:557-562.

5I. Brown KT, Koh BY, Brody LA, Getrajdman GI, Susman J, Fong Y, Blumgart LH: Particle embolization of hepatic neuroendocrine metastases for control of pain and hormonal symptoms. J Vasc Interv Radiol 1999, 10:397-403.

52. Oberg K: Endocrine tumors of the gastrointestinal tract: systemic treatment. Anticancer Drugs 1994, 5:503-519.

53. Jacobsen MB, Hanssen LE: Clinical effects of octreotide compared to placebo in patients with gastrointestinal neuroendocrine tumours. Report on a double-blind, randomized trial. J Intern Med 1995, 237:269-275.

54. Prvulovich EM, Stein RC, Bomanji JB, Ledermann JA, Taylor I, Ell PJ: lodine-I3 I-MIBG therapy of a patient with carcinoid liver metastases. J Nucl Med 1998, 39: 1743-1745.

55. Safford SD, Coleman RE, Gockerman JP, Moore J, Feldman J, Onaitis MW, Tyler DS, Olson JA Jr: lodine-13I metaiodobenzylguanidine treatment for metastatic carcinoid. Cancer 101:1987-1993. 28-9-2004

56. Oberg K, Eriksson $\mathrm{B}$ : The role of interferons in the management of carcinoid tumours. $\mathrm{Br} J$ Haematol I991, 79(Suppl I):74-77.

57. Faiss S, Pape UF, Bohmig M, Dorffel Y, Mansmann U, Golder W, Riecken EO, Wiedenmann B: Prospective, randomized, multicenter trial on the antiproliferative effect of lanreotide, interferon alfa, and their combination for therapy of metastatic neuroendocrine gastroenteropancreatic tumors - the International Lanreotide and Interferon Alfa Study Group. J Clin Oncol 21:2689-2696. 15-7-2003

58. Pape UF, Wiedenmann B: Adding interferon-alpha to octreotide slows tumour progression compared with octreotide alone but evidence is lacking for improved survival in people with disseminated midgut carcinoid tumours. Cancer Treat Rev 2003, 29:565-569.

59. Schally AV, Nagy A: Cancer chemotherapy based on targeting of cytotoxic peptide conjugates to their receptors on tumors. Eur J Endocrinol | 999, I 4 I: I- | 4 .

60. Nagy A, Schally AV: Targeted cytotoxic somatostatin analogs: a modern approach to the therapy of various cancers. Drugs Future 200I, 26:26I-270

61. De Jong M, Valkema R, Jamar F, Kvols LK, Kwekkeboom DJ, Breeman WA, Bakker WH, Smith C, Pauwels S, Krenning EP: Somatostatin receptor-targeted radionuclide therapy of tumors: preclinical and clinical findings. Semin Nucl Med 2002, 32: I33- 140.

62. Lam MG, Lips CJ, Jager PL, Dullaart RP, Lentjes EG, van Rijk PP, de Klerk JM: Repeated [I3II]metaiodobenzylguanidine therapy in two patients with malignant pheochromocytoma. J Clin Endocrinol Metab 2005, 90:5888-5895.

63. Florman S, Toure B, Kim L, Gondolesi G, Roayaie S, Krieger N, Fishbein T, Emre S, Miller C, Schwartz M: Liver transplantation for neuroendocrine tumors. J Gastrointest Surg 2004, 8:208-2 12

64. Penn I: Hepatic transplantation for primary and metastatic cancers of the liver. Surgery 199I, I 1 0:726-734.

65. Le Treut YP, Delpero JR, Dousset B, Cherqui D, Segol P, Mantion G, Hannoun L, Benhamou G, Launois B, Boillot O, Domergue J, Bismuth $\mathrm{H}$ : Results of liver transplantation in the treatment of metastatic neuroendocrine tumors. A 3 I-case French multicentric report. Ann Surg 1997, 225:355-364.

66. Lehnert T: Liver transplantation for metastatic neuroendocrine carcinoma: an analysis of 103 patients. Transplantation 66:1307-I3|2. 27-II-1998

67. Ahlman H, Friman S, Cahlin C, Nilsson O, Jansson S, Wangberg B, Olausson M: Liver transplantation for treatment of metastatic neuroendocrine tumors. Ann N Y Acad Sci 2004, I0 1 4:265-269. 